\title{
Estimation of Vascular Cell Adhesion Molecule 1 (VCAM-1) Levels In Type 1 Diabetic Mellitus Patients
}

Abstract: High glucose levels in patients with diabetes are associated with increased plasma levels of soluble adhesion molecules. They could explain that the patients with diabetes mellitus will require the development of premature atherosclerosis related to hyperglycemia or hyperinsulinemia and that it not only affects vascular endothelium but also contributes to the development of microvascular complications. This study aimed to evaluate the serum concentration of VCAM- 1 in type 1 diabetes mellitus patients with and without cardiovascular disease. Also, investigation the association of insulin levels, duration of diabetes, and $\mathrm{HbAlC}$ with VCAM-1. Include in this study a total of 60 types 1 diabetic patient. According to characteristic laboratory investigations and electrocardiogram (ECG), they were subdivided into two groups (G1) 30 T1DM patients without cardiovascular disease and (G2) 30 T1DM patients with cardiovascular disease in addition to 30 healthy subjects as a control group (G3). All subjects measured the levels of fasting blood glucose FBG, glycated hemoglobin HbAlc, and insulin levels, and VCAM-1 were also determined by ELISA technique. This study shows a highly significant difference in the average diabetic profile between G1 and G2 compared to the control group and found that VCAM-1 level was significantly higher among diabetic patients than the control group. Also, there was a significant negative correlation of VCAM-1 with the levels of FBG, HbAlc in diabetic patients G1 and $\mathrm{G} 2$. While insulin had a positive correlation in $\mathrm{G}$ but correlated negatively in $\mathrm{G} 2$.

Key words: TIDM, CVD, VACAM-1, adhesion molecule, insulin.

\section{Introduction}

Diabetes mellitus type 1 is a chronic metabolic disease caused by autoimmune pancreatic beta-cell destruction that leads to insulin deficiency and is more commonly diagnosed in young adults, and they are at high risk of micro-and macrovascular complications develop ${ }^{1}$. Type 1diabetes Mellitus is considered a significant risk factor for cardiovascular disease (CVD) because of poor metabolic control, long duration of disease, and existing dyslipidemia or hypertension².

Vascular infiltration affected by adhesion molecules and that released by damaged endothelial cells or inflammatory conditions entering into the arterial wall. Adhesion molecules such as vascular cell adhesion molecule 1 (VCAM-1) and intercellular adhesion molecule 1 (ICAM-1) act as atherosclerosis markers isolated from the endothelium and measured in peripheral blood, and also, VCAM-1 has a role in autoimmune diseases ${ }^{3,4}$. The soluble forms of adhesion molecules found in the serum of diabetic patients, that activation suggested endothelial of a role in diabetes ${ }^{5}$. High glucose levels in patients with diabetes participate in increased plasma levels of soluble adhesion molecules. Therefore, they could explain that the patients with diabetes mellitus will develop premature atherosclerosis related to hyperglycemia or hyperinsulinemia and that it not only affects vascular endothelium but also contributes to the development of microvascular complications ${ }^{6}$.

The endothelial function is considered a marker of vascular dysfunction and is a good predictor of cardiovascular disease, irregularity in the endothelial function involves the pathogenesis of cardiovascular diseases ${ }^{7}$. An increase in the serum levels of cellular adhesion molecules, ICAM-1 and VCAM-1, as specific markers of endothelial dysfunction indicates an impaired endothelial function ${ }^{8}$. Local researches in VCAM-1 to predict complicate of type 1 diabetes mellitus on the cardiovascular are limited. So that, the aim of this study was estimated
VCAM-1 levels in serum of type 1 diabetes patients with and without cardiovascular disease. Also, investigation the association of insulin levels, duration of diabetes, and $\mathrm{HbA} 1 \mathrm{C}$ with VCAM-1.

\section{Methods}

This study includes 60 types 1 diabetic patient diagnosed by consultant physicians enrolled in "National Diabetic Center (NDC)" Baghdad - Iraq, from December to March 2018. According to characteristic laboratory investigations and electrocardiogram (ECG), they were subdivided into two groups as follows: (G1) 30 T1DM patients without cardiovascular disease the mean age (15 \pm 6.67$)$ years and (G2) include 30 T1DM patients with cardiovascular disease their mean age $(10 \pm 5.81)$ years in addition to 30 healthy subjects as a control group with mean age (17 \pm 3.12$)$ years. This study excluded patients with autoimmune disease, any stage of heart failure, thyroid disease, and uncontrolled hypertension.

A blood sample from all subjects was drawn to measure the levels of fasting blood glucose $\mathrm{FBG}^{9}$, glycated hemoglobin $\mathrm{HbAlc}^{10}$. Levels of insulin and VCAM-1 were also determined by ELISA technique ${ }^{11}$. And body mass index BMI was calculated for each subject in patients and control groups.

\section{Statistical analysis}

All data of this study submitted as (mean \pm SD). The student's T-test was applied to compare patient groups with the healthy group; also, Pearson's coefficient was used for correlation analysis.

\footnotetext{
${ }^{1}$ Dept. of Medical Laboratory Technologies - College of Health and Medical Technologies, Middle Technical University, Iraq
}

${ }^{2}$ Dept. of Community Health- Baghdad -Medical Technical Institute, Middle Technical University, Iraq. 


\section{Results}

This study involved sixty T1DM patients and thirty healthy controls. Table (1) listed demographic data of patient groups G1, G2, and healthy control G3. The mean age of the patient groups was ( $15 \pm 6.67$ and $10 \pm 5.81$ ) years in $\mathrm{Gl}$ and $\mathrm{G} 2$, respectively, with significant differences and distribution of sex was non-significant between studied groups. Mean BMI was normal in the patient's group and control group with significant difference between patients group when compared to control group.

Data in table 2 shown as expected a highly significant difference $(p<0.001)$ in an average of diabetic profile (fasting blood glucose (FBG), glycated hemoglobin ( $\mathrm{HbAlc}$ ) and insu(in) between $\mathrm{G} 1$ and $\mathrm{G} 2$ when compared to the control group were also found, VCAM-1 level was significantly higher among diabetic patients than the control group.

In addition, there was a significant negative correlation of VCAM-1 with the levels of FBG, HbAlc in diabetic patients $\mathrm{Gl}$ and $\mathrm{G} 2$. At the same time, insulin had a positive correlation in G1 but correlated negatively in $\mathrm{G} 2$, as in table 3 .

\section{Discussion}

This study compared mean FBG, HbAlc, and insulin with VCAM-1 between sixty T1DM patients with and without CVD and 30 healthy adolescents. As expected, levels of FBG, $\mathrm{HbAlc}$, and insulin were significantly higher in patient groups. T1DM is caused by insulin deficiency; hyperglycemia, and that could damage the vascular ${ }^{12}$. The levels of VCAM-1 was highly significantly increased in G1 and G2 compared to control similar group result in the study by other researcher ${ }^{13,14}$ who found the levels of endothelial markers including VCAM-1 were higher in adults with T1DM than control, while there is no data available about levels of VCAM-1 in T1DM with CVD. Increased VCAM-1 as an adhesion molecule leads to endothelial dysfunction as a part of the inflammatory process ${ }^{15}$. T1DM may lead to increased VCAM-1, damage endothelial vascular as a result of that adhesion molecule will expression ${ }^{16}$. Therefore the risk of atherosclerosis will increase and the mortality due to cardiovascular complications in T1DM patients ${ }^{17}$.

According to the current study, VCAM-1 was significantly associated with FBG, $\mathrm{HbAlc}$, and insulin in both patients and control groups. These findings disagree with the results of another researcher; they reported no correlation between serum level of VCAM-1 with FBG, HbAlc, and duration of disease $^{18}$. Insulin resistance will increase the expression of adhesion molecules like VCAM-1 molecule ${ }^{19}$. So, in diabetic patients, elevated $\mathrm{HbAlc}, \mathrm{FBG}$, and increased insulin level due to insulin resistance ${ }^{20}$

\section{Conclusions}

As VCAM-1 level was significantly higher in both patient groups with and without cardiovascular disease so that, maybe we assume that it used to predictive to cardiovascular disease in T1DM patients, also; we suggested that if the patient with T1DM uses pro-inflammatory medical agents in their protocol, treatment can cause prevention complication of diabetic microvascular in future. The limitation of this study was the small sample size, and patients should be selected from a different area of Iraq. Also, HbAlc represents the average blood glucose during three months, and if the mean level of $\mathrm{HbAlc}$ may be more helpful.

\begin{tabular}{|c|c|c|c|c|}
\hline & $\begin{array}{c}\text { G1 } \\
\text { Without CVD } \\
\text { N=30 }\end{array}$ & $\begin{array}{c}\text { G2 } \\
\text { With CVD } \\
\text { N=30 }\end{array}$ & $\begin{array}{c}\text { G3 } \\
\text { Control group } \\
\text { N=30 }\end{array}$ & P-value \\
\hline Age (Yrs) & $15 \pm 6.67$ & $10 \pm 5.81$ & $17 \pm 3.12$ & NS \\
\hline $\begin{array}{c}\text { Sex } \\
\text { (male/female) }\end{array}$ & $15 / 15$ & $14 / 16$ & $16 / 14$ & $\mathrm{~S}$ \\
\hline $\begin{array}{c}\text { Duration of } \\
\text { DM (Yrs) }\end{array}$ & $2 \pm 0.57$ & $1 \pm 0.29$ & ------ & NS \\
\hline BMI & $22.31 \pm 8.26$ & $19.90 \pm 4.68$ & $23.94 \pm 4.77$ & HS \\
\hline
\end{tabular}

Statistically significant (S) considered when P-values was $<0.05$ and (HS) highly significant difference considered when P-values was $<0.001$.

Table 1. Clinical characteristics of the patients and control groups.

\begin{tabular}{|c|c|c|c|c|}
\hline & $\begin{array}{c}\text { G1 } \\
\text { Without CVD }\end{array}$ & $\begin{array}{c}\text { G2 } \\
\text { With CVD }\end{array}$ & $\begin{array}{c}\text { G3 } \\
\text { Control group }\end{array}$ & P-value \\
\hline $\begin{array}{c}\text { FBG } \\
\text { (mg/dl) }\end{array}$ & $274.4 \pm 111.5$ & $264.4 \pm 96.07$ & $85.90 \pm 7.24$ & $<0.001$ \\
\hline HbA1c \% & $10.49 \pm 2.30$ & $10.98 \pm 2.39$ & $5.05 \pm 0.46$ & $<0.001$ \\
\hline $\begin{array}{c}\text { Insulin } \\
\text { (MU/mL) }\end{array}$ & $17.49 \pm 3.74$ & $20.88 \pm 3.12$ & $12.15 \pm 2.31$ & $<0.001$ \\
\hline $\begin{array}{c}\text { VCAM-1 } \\
(\mathbf{n g} / \mathbf{m L})\end{array}$ & $26.40 \pm 4.43$ & $41.35 \pm 4.47$ & $20.17 \pm 3.49$ & $<0.001$ \\
\hline
\end{tabular}

Statistically significant considered when $\mathrm{P}$-values was $<0.05$ and highly significant difference considered when P-values was $<0.001$

Table 2. Clinical characteristics of the patients and control groups. 


\begin{tabular}{|c|c|c|c|}
\hline & & G1 & G2 \\
\hline VCAM-1 \& FBG & $\mathrm{r}$ & -0.304 & -0.219 \\
\cline { 2 - 4 } & $\mathrm{p}$ & 0.102 & 0.214 \\
\hline \multirow{2}{*}{ VCAM-1 \& HbA1c } & $\mathrm{r}$ & -0.224 & -0.059 \\
\cline { 2 - 4 } & $\mathrm{p}$ & 0.234 & 0.738 \\
\hline VCAM-1\&duration of disease & $\mathrm{r}$ & -0.420 & 0.003 \\
\cline { 2 - 4 } & $\mathrm{p}$ & 0.021 & 0.986 \\
\hline VCAM-1 \& Insulin & $\mathrm{r}$ & 0.088 & -0.172 \\
\cline { 2 - 4 } & $\mathrm{p}$ & 0.643 & 0.329 \\
\hline
\end{tabular}

Statistically significant considered when P-values was $<0.05$ and highly significant difference considered when P-values was $<0.001$.

Table 3. Correlate of vitamin D with some variables.

\section{Acknowledgments and funding}

This study received no specific grant from any funding agency in the public, commercial, or not-for-profit sectors.

\section{Conflict of interest}

The authors declare that they have no conflict of interest.

\section{Bibliographic references}

1. American Diabetes Association's, Standards of medical care in diabetes-2020, Diabetes Care. 2020; 43 (1): S14-S31.

2. Musina NN, Saprina VT, Kanev A, Prokhorenko ST, Zima PA. Correlations between iron metabolism parameters, inflammatory markers and lipid profile indicators in patients with type 1 and type 2 diabetes mellitus, J. Personalized Med. 2020; 10 (3): 70.

3. Nusrianto R, Tahapary D, Soewondo P. Visceral adiposity index as a predictor in an Asian population: a systematic review, Diabetes \& Metabolic Syndrome: Clin. Res. Rev. 2019; 13(2): 1231-1235.

4. Schlesinger M., Bendas G. Vascular cell adhesion molecule-1 (VCAM-1) an increasing insight into its role in tumorigenicity and metastasis. Int. J. Cancer 2015; 136: 2504-2514.

5. Kong D, Kim Y, Kim M, Jang J and Lee S. Emerging Roles of Vascular Cell Adhesion Molecule-1(VCAM-1) in Immunological Disorders and Cancer. Int. J. Mol. Sci. 2018; 19: 1057.

6. Sinem F, Emre H, Saribal D, Yenmis G, Guvenen G. Vascular Cell Adhesion Molecule 1, Intercellular Adhesion Molecule 1, and Cluster of Differentiation 146 Levels in Patients with Type 2 Diabetes with Complications. Endocrinol Metab 2017; 32: 99-105.

7. Kalani M. The importance of endothelin 1 for microvascular dysfunction in diabetes. Vasc Health Risk Manag. 2018; 4:1061-8.

8. Altannavch TS, Roubalova K, Kucera P, et al. Effect of high glucoseconcentrations on expression of ELAM-1, VCAM-1 and ICAM1 in HUVEC with and without cytokine activation. Physiol Res. 2004; 3:77-82.

9. Bartham D., Trrinder P. An improved color reagent from the determination of blood glucose by the oxidation system. Analyst, 1972; 97: 142-145.

10. Jeppson JO, Kobold U, Barr J, Finke A, Weykamp C. Approved IFCC reference method for the measurement of $\mathrm{HbAlc}$ in human blood, Clin Chem Lab Med. 2002; 40(1): 78- 89 .

11. Votila M, Rouslahti E, Engvall E. Two site sandwich enzyme immunoassay with monoclonal antibodies to human. Alghafetoprotein J Immunl Methods.1981; 42(1): 11-5.

12. Sarwar N, Gao P, Seshasai SR, Gobin R, Kaptoge S, Di Angelantonio $\mathrm{E}$, et al. Diabetes mellitus, fasting blood glucose concentration, and risk of vascular disease: a collaborative meta-analysis of 102 prospective studies. Lancet.2010; 375 (9733): 2215-22.
13. Ahmadi A, Soori H, Khaledifar A. In-hospital case fatality rate and cox proportionalhazards model for risk factors of mortality due to myocardial infarction. International Cardiovascular Research Journal. 2015; 9:159-63.

14. Rostampour N, Fekri K, Dehkordi D, Obodiat M. Association between Vascular Endothelial Markers and Carotid Intima-Media Thickness in Children and Adolescents with Type 1 Diabetes Mellitus. Journal of Clinical and Diagnostic Research. 2017; 11(9): SCO1-SC05.

15. Fusaro MF, Zanini JL, Silva IN. Increased carotid intima-media thickness in Brazilian adolescents with type 1 diabetes mellitus. Diabetol Metab Syndr. 2016; 8:74

16. Rad MP, Farrokh D, Vakili R, Omidbakhsh, Mohammadi M. The association between carotid intima-media thickness and the duration of type 1 diabetes in children. Iran J Paediatr. 2014; 24(3): 249-54.

17. Cerutti C, Ridley AJ. Endothelial cell-cell adhesion and signaling. Exp. Cell Res. 2017, 358, 31-38.

18. Hadi HA, Suwaidi JA. Endothelial dysfunction in diabetes mellitus. Vasc Health Risk Manag 2007; 3:853-76.

19. Ruszkowska-Ciastek B, Sokup A, Wernik T, Ruprecht Z, Goralczyk B, Goralczyk K, et al. Effect of uncontrolled hyperglycemia on levels of adhesion molecules in patients with diabetes mellitus type 2. J Zhejiang Univ Sci B 2015; 16: 355- 61.

20.Ugurlu N, Gerceker S, Yulek F, Ugurlu B, Sari C, Baran P, et al. The levels of the circulating cellular adhesion molecules ICAM-1, VCAM-1 and endothelin-1 and the flow-mediated vasodilatation values in patients with type 1 diabetes mellitus with early-stage diabetic retinopathy. Intern Med 2013; 52: 2173-8.

Received: 7 september 2021

Accepted: 30 October 2021 